\title{
NORMAL CORONARY ANGIOGRAM;
} CLINICAL CHARACTERISTICS OF PATIENTS.

1. MBBS. FCPS (Cardiology) Assistant Professor of Cardiology, University Medical \& Dental College. Head of Cardiology Department, Madinah Teaching Hospital, Faisalabad.

2. MBBS. FCPS (Cardiology) Senior Registrar of Cardiology, Faisalabad Institute of Cardiology.

3. MBBS. FCPS (Cardiology) Senior Registrar of Cardiology, Wazirabad Institute of Cardiology.

Correspondence Address:

Dr. Naeem Asghar

Assistant Professor of Cardiology, University Medical \& Dental College. Head of Cardiology Department, Madinah Teaching Hospital,

Faisalabad.

dearnaeem06@gmail.com

Article received on:

06/06/2017

Accepted for publication:

15/07/2017

Received after proof reading: 08/09/2017

\section{Naeem Asghar ${ }^{1}$, M. Faiq llyas ${ }^{2}$, Muhammad Nazim ${ }^{3}$}

ABSTRACT... Objectives: To observe the clinical characteristics of patients having normal coronary angiogram following an abnormal stress test or presented with chest pain indicating coronary angiogram. Study Design: A single center retrospective, descriptive study. Period: Coronary angiograms done from September 2015 to September 2016 were retrieved and reviewed for normal coronary arteries. Setting: Khatum-un-Nabyeen Heart Center. Methodology: Clinical profile of the patients having normal coronary angiogram was retrieved from hospital record. Results: Out of 900 angiograms reviewed, $81(9 \%)$ were having normal coronary arteries. Mean age was $43 \pm 10$ years. Females were $64.1 \%$. Clinical characteristic of study group was as follows: smokers $32.09 \%$, family history of premature coronary artery disease $51.8 \%$, hyperlipidemia $60.4 \%$ and hypertension $19.7 \%$. Diabetes was present only in $20.9 \%$. Among females: $19.2 \%$ were current users of oral contraceptives pills and $13.4 \%$ were post menopausal. Mean BMI was $25.4 \pm 4$. Conclusion: Normal coronary angiogram is infrequent observation in cardiac catheterization laboratories and mostly found in younger to middle aged females. Family history of coronary artery disease and hyperlideimaare very common in such patients.

Key words: Normal Coronary Angiogram, Clinical Characteristics.

Article Citation: Asghar N, llyas MF, Nazim M. Normal coronary angiogram; clinical characteristics of patients. Professional Med J 2017;24(9):1271-1274.

DOI:10.17957/TPMJ/17.4109

\section{INTRODUCTION}

Routinely patients in cardiology clinic are assessed based on their chest pain characteristics, coronary risk profile, and the results of noninvasive investigation. ${ }^{1-3}$ The 'typical', 'atypical' and 'non-cardiac' chest pain are subjective terms with wide range of interpretation. ${ }^{4}$ Usually $16-$ $20 \%$ of patients in cardiology clinic has chest pain not related to cardiac disease while in referred patients only $11-27 \%$ has cardiac diseases. ${ }^{5,6}$ Between $11 \%$ and $37 \%$ of cases referred for cardiac workup the coronary angiogram shows normal coronary vessels. ${ }^{7}$ However the term syndrome $X$ is used for those who present with chest pain and abnormal stress tests results but normal coronary arteries. ${ }^{8,9}$ Number of non-cardiac conditions are associated chest pain.9,10 This differentiation between cardiac and non-cardiac conditions presenting with chest pain is often difficult but have great importance for trearment. ${ }^{11}$ Similarly in a some patients, Myocardial Infarction (MI) is caused by coronary Artery Disease (CAD) and thrombosis, embolism, vasospasm and smoking are believed to be the mechanisms other than atherosclerosis leading to ischemia. ${ }^{12-20}$ Literature review shows that patients with normal coronary angiogram are young and they lack classic risk factors for CAD. However there is significant geographical variation.This study was designed to identify clinical characteristics of patients with normal coronary angiogram to avoid invasive investigations and reduce unnecessary cost and burden on our catheterization laboratory.

\section{PATIENTS AND METHODS}

This was a single center retrospective, descriptive study. Patients of either gender with age 30 years or more, who had coronary angiography, in Khatum-un-Nabyeen Heart Center were included in the study. Coronary angiograms performed from September 2015 to September 2016 were evaluated for the presence of normal 
coronary angiogram. Patients with normal coronary angiograms were included in the study by using non-probability, purposive sampling technique. Following ethical and research approval from the hospital administration, clinical profile of the patients having normal coronary angiogram were retrieved from hospital record. Clinical profile included: age, gender, Body Mass Index (BMI), smoking status, presence of hypertension, diabetes mellitus and family history of coronary artery disease. In cases of female patients postmenopausal status and use of oral contraceptive pills was also noted. SPSS version 16.0 was used for analyzing the data. Frequency and percentages were used for categorical variables. Mean $\pm S D$ was used for numerical variables. Data were presented in the form of tables.

\section{OBJECTIVE}

To observe the clinical characteristics of patients having normal coronary angiogram following an abnormal stress test or presented with chest pain indicating coronary angiogram.

\section{Inclusion criteria}

1. Patients admitted with acute coronary syndrome.

2. Patients with history of chest pain and abnormal noninvasive stress test.

\section{Exclusion criteria}

1. Patients, who had normal coronary angiograms but their clinical and bio-chemical profile could not be traced in hospital record.

2. Patients with current pregnancy.

3. Previous history of $\mathrm{PCl}$.

4. Documented coronary artery disease in previous angiogram.

\section{OPERATIONAL DEFINITIONS}

\section{Normal coronary angiogram}

It was defined as, smooth outline of coronary arteries-confirmed in multiple planes as reported by atleast two cardiologists.

\section{Hyperlipidemia}

Patients with LDL level greater than $130 \mathrm{mg} / \mathrm{dl}$ were labeled as hyperlipidemic.

\section{RESULTS}

Table-I shows frequency of normal coronary angiogram. Among 900 coronary angiograms were studied of which $81(9 \%)$ patients had a normal coronary angiogram. The clinical characteristics of patients with normal coronary angiogram are documented in Table-l.

\begin{tabular}{|l|c|}
\hline \multicolumn{1}{|c|}{ Parameter } & N (\%) \\
\hline Patients having Normal coronary angiogram & $81(9 \%)$ \\
\hline $\begin{array}{l}\text { Patients with documented coronary artery } \\
\text { disease. }\end{array}$ & $819(91 \%)$ \\
\hline \begin{tabular}{l} 
Table-I. Frequency of normal coronary angiogram. \\
\hline
\end{tabular}
\end{tabular}

\begin{tabular}{|l|c|}
\hline \multicolumn{1}{|c|}{ Parameter } & N (\%) \\
\hline Age & $43 \pm 10$ years \\
\hline BMI & $25.4 \pm 4$ \\
\hline Male & $29(35.8 \%)$ \\
\hline Female & $52(64.1 \%)$ \\
\hline Smoker & $26(32.09 \%)$ \\
\hline Family history of CAD & $42(51.8 \%)$ \\
\hline Hyperlipidemia & $49(60.4 \%)$ \\
\hline Hypertension & $16(19.7 \%)$ \\
\hline Diabetes Mellitus & $17(20.98 \%)$ \\
\hline Female Using Oral Contraceptive Pills & $10(19.2 \%)$ \\
\hline Post Menopausal Women & $7(13.4 \%)$ \\
\hline \multicolumn{2}{|c|}{ Table-II. Clinical characteristics } \\
\hline
\end{tabular}

\section{DISCUSSION}

Coronary angiogram is the gold standard for detecting significant coronary artery disease (CAD). In our study, we observed that Normal coronary angiography (NCA) is not commonly reported from cardiac catheterization laboratories. However its frequency is common in younger to middle aged females and their cardiovascular risk factor profile shows hyperlidemia and having family history of CAD as the most common risk factor that why these patients are frequently investigated with coronary angiogram. Among other risk factors are smoking, diabetes and hypertension while in female patients use of oral contraceptive and post menopausal status are additional risk factor for cardiovascular disease. These finding are supported by other international studies; Greenberg et $\mathrm{al}^{14}$ reported that smoking was present in $52 \%$ of patients with NCA. Similarly, Chambers et $\mathrm{al}^{6}$ observed that 
$61 \%$ of patients were smokers at the time of NCA. The proposed reasons in literature for normal coronary angiography among smokers are; smoking induces spasm in coronary arteries ${ }^{3}$ and smoking also causes coronary artery endothelial dysfunction that leads to platelets activation ${ }^{2}$ and oxidative stress leading to abnormal myocardium perfusion and ischemia at micro vascular level. ${ }^{14}$ However in our study smoking was most frequent risk factor in male patients but overall smoking was not major risk factor because mostly female were included in the study and there lower trend of smoking in women in Pakistan. Family history of premature coronary artery diseases (CAD) is major risk factor that was present in $51.8 \%$ patients with normal coronary angiography in our study. This frequency is higher compared to western data. $\mathrm{Wu}$ et $\mathrm{al}^{1}$ documented that $23 \%$ patients with NCA were having family history of premature CAD. We assumed that those who had seen their close relatives suffering from CAD or death of any close relative due to a cardiac event, they become more sensitive to chest pain. Their threshold to chest pain becomes lower and mostly they insist for coronary angiography. This trend is also observed mostly in Indian subcontinent region but less frequently in western world. ${ }^{20}$ Diabetes mellitus was observed in just $22.8 \%$ patients this frequency is higher than reported by Chambers $\mathrm{J}$ et $\mathrm{al}^{6}$ and Proudfit et al ${ }^{12}$; i-e; $5.3 \%$ and $3.7 \%$, respectively. This explains that increasing trend of diabetes in Asians however diabetes mellitus is associated with diffuse and severe coronary artery disease..$^{9,13}$ The theories to explain chest pain in diabetics with normal coronary angiogramare: impaired coronary vascular reactivity ${ }^{3}$, subendocardialhypoperfusion detected by $3 T$ MRI3, micro vascular dysfunction ${ }^{13}$, metabolic abnormalities-such as net myocardial lactate production $^{14}$, sustained coronary spasm ${ }^{3}$, vasculitis ${ }^{15}$, coagulopaties ${ }^{15}$ and misinterpretation of coronary angiograms. ${ }^{12}$ Improving the clinical assessment and non-invasive cardiac stress testing will lower the referral rate of patients with on-cardiac/atypical chest pain for invasive coronary artery angiogram..

\section{CONCLUSION}

Normal coronary angiogram is infrequent observation in cardiac catheterization laboratories and mostly found in younger to middle aged females. Family history of coronary artery disease and hyperlideimaare very common in such patients.

\section{Copyright(C) 15 July, 2017}

\section{REFERENCES}

1. Wu EB, Hudson F, Chambers JB. A simple score for predicting coronary artery disease in patients with chest pain. QJM 2005; 98:803-11.

2. Iuliano L, Micheletta F, Napoli A, Catalano C. Myocardial infarction with normal coronary arteries: a case report and review of the literature. J Med Case Rep 2009; 3:24.

3. Yee T, Chang A, Kotys M, Holper E, Peshock R. Impaired coronary vascular reactivity in cardiac syndrome $X$ measured non-invasively by $3 T$ MRI. J Am Coll Cardiol 2010; 55:A82.E775.

4. Hotopf M, Mayou R, Wadsworth M, Wessely S. Psychosocial and developmental antecedents of chest pain in young adults. Psychosom Med 1999; $61: 861-7$.

5. Savage DD, Devereux RB, Garrison RJ, Castelli WP, Anderson SJ. Mitral valve prolapse in the general population. Clinical features: the Framingham Study. Am Heart J 1983; 106:577-81.

6. Chambers J, Bass C. Chest pain with normal coronary anatomy: a review of natural history and possible etiologic factors. Prog Cardiovasc Dis 1990; 33:16184.

7. Kroenke $K$, Mangelsdorff AD. Common symptoms in ambulatory care: incidence, evaluation, therapy, and outcome. Am J Med 1989; 86:262-6.

8. Jain D, Fluck D, Sayer JW, Ray S, Paul EA, Timmis AD. Onestop chest pain clinic can identify high cardiac risk. J R Coll Physicians Lond1997; 31:401-4.

9. Newby DE, Fox KAA, Flint LL, Boon NA. A 'same day' direct-access chest pain clinic: improved management and reduced hospitalization. QJM 1998; 91:333-7.

10. Sutcliffe SJ, Fox KF, Wood DA. How to set up and run a rapid access chest pain clinic. $\mathrm{Br} J$ Cardiol2000; 7:692-702.

11. Davie AP, Caesar D, Caruana L, Clegg G, Spiller J, Capewell $S$, et al. Outcome from a rapid-assessment chest pain clinic. QJM 1998; 91:339-43. 
12. Proudfit WL, Shirey EK, Sones FM. Selective cinecoronary arteriography: correlation with clinical findings in 1,000 patients. Circulation 1966; 33:901-10.

13. Kemp HG, Kronmal RA, Vliestra RE, Frye RL. Seven years survival of patients with normal or near normal coronary arteriograms: a CASS registry study. J Am Coll Cardiol1986; 7:479-83.

14. Greenberg MA, Grose RM, Neuburger N, Silverman R, Strain JE, Cohen MV. Impaired coronary vasodilator responsiveness as a cause of lactate production during pacing-induced ischaemia in patients with angina pectoris and normal coronary arteries. $\mathrm{J} \mathrm{Am}$ Coll Cardiol1987; 9:743-51.

15. Alpert JS. Myocardial infarction with angiographically normal coronary arteries. Arch Intern Med 1996; 154:2659.

16. Da Costa A, Isaaz K, Faure E, Mourot S, Cerisier A, Lamaud M. Clinical characteristics, aetiological factors and longterm prognosis of myocardial infarction with an absolutely normal coronary angiogram: a 3-year follow-up study of 91 patients. Eur Heart J 2001; 22:1459-65.

17. Bugiardini R, BaireyMerz CN. Angina with "normal" coronary arteries: a changing philosophy. JAMA 2005; 293:47784.

18. Thygesen $\mathrm{K}$, Alpert JS, White HD. Universal definition of myocardial infarction. Eur Heart J 2007; 28:252538.

19. Zimmerman $\mathrm{FH}$, Cameron A, Fisher LD, $\mathrm{Ng}$ G. Myocardial infarction in young adults: angiographic characterization, risk factors and prognosis (Coronary Artery Surgery Study Registry). J Am Coll Cardiol1995; 26:654-61.

20. Legrand V, Deliege M, Henrard L, Boland J, Kulbertus $\mathrm{H}$. Patients with myocardial infarction and normal coronary arteriogram. Chest 1982; 82:678-85.

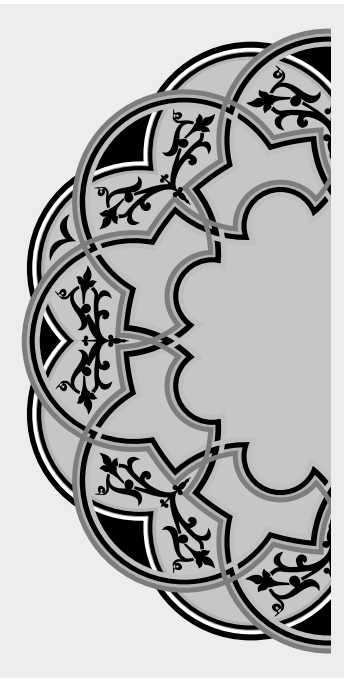

\author{
"When you make a commitment, \\ you build hope. \\ When you keep it, you build trust."
}

\author{
Unknown
}

\title{
AUTHORSHIP AND CONTRIBUTION DECLARATION
}

\begin{tabular}{|c|l|l|l|}
\hline Sr. \# & \multicolumn{1}{|c|}{ Author-s Full Name } & \multicolumn{1}{|c|}{ Contribution to the paper } & \multicolumn{1}{|c|}{ Author=s Signature } \\
\hline 1 & Dr. Naeem Asghar & Data collection \\
\hline 2 & Dr. M. Faiq llyas & Drafting \\
\hline 3 & Dr. Muhammad Nazim & Statistical analysis \\
\hline
\end{tabular}

